\title{
Crystallographic Properties of the Unsupported Ni-Mo Carbides Phases
}

\author{
Adriana Isabel Reyes de la Torre ${ }^{1 *}$, José Aarón Melo Banda ${ }^{1}$, Ulises Paramo García ${ }^{1}$, \\ Diana Isela Sánchez Alvarado ${ }^{1}$, \\ Marco Antonio Coronel García ${ }^{1,2}$, Benjamín Portales Martínez ${ }^{2}$ \\ ${ }^{1}$ Madero City Institute of Technology, Madero City, Mexico \\ ${ }^{2}$ Mexican Petroleum Institute, Molecular Engineering Program, Mexico City, Mexico \\ Email: *airt22@hotmail.com
}

Received February 21, 2013; revised March 20, 2013; accepted April 1, 2013

Copyright (C) 2013 Adriana Isabel Reyes de la Torre et al. This is an open access article distributed under the Creative Commons Attribution License, which permits unrestricted use, distribution, and reproduction in any medium, provided the original work is properly cited.

\begin{abstract}
In the present work, the crystallographic properties of unsupported Ni-Mo catalyst serie were carried out. They were synthesized with a ratio of Mo from 10, 25, 50 to $75 \mathrm{wt} \%$. The final catalysts were characterized by X-ray diffraction (XRD) in order to identify crystallographic phases present in the solids using DRXwinsoftware version 2.3. The crystal size was determinated by Bragg's law. Ni-Mo catalyst model (MoC-75) structure was modeled by Carine Crystallography Software version 3.1 which was built based on its space group and atomic positions which were previous the results of XRD. Characteristical phases of Ni-Mo Carbides were identified for their typical planes (111), (200) and (311) for Ni-Mo series and the plane (101) for the $\alpha$ Mo-C series.
\end{abstract}

Keywords: Catalysts; Carbides; Crystallography; Ni-Mo; Molybdenum; Nickel

\section{Introduction}

The research of new catalytic materials has attracted special interest in the preparation of ceramic composites, such as transition metal carbides with high surface areas [1]. These materials have high strength and catalytic activities, for example for use in hydrotreating processes. Within this type of new materials, the most studied solids are molybdenum carbides, due to their similar activities to a commercial catalyst of $\mathrm{NiMo} / \mathrm{Al}_{2} \mathrm{O}_{3}$ in hydrotreating reactions. Ramathan et al. [2], used molybdenum carbide for hydrogenation reactions of CO. In 1994, Vrinat et al. [3], determinate a certain properties of hydrotreating catalyst of sulfides metals, they also describe a specific property as the carbide materials for typical HDS reactions. The catalyic properties of the carbides are determined by their structural form, phases and metals contents in the materials. The characterization of the properties of the catalysts is important for the design and manufacture industrial scale also for the optimization of industrial catalytic processes. The main purpose is to understand the relationship between the selectivity of the catalyst to their physical and chemical properties and the fi-

"Corresponding author. nal activity properties for their final use on catalytic purpose.

In this paper, the final structure of carbide catalysts of unsupported Ni-Mo material was suited. This behavior was analyzed using experimental data, adjusted to a theoretical model from the pattern of X-ray diffraction. The diffraction pattern is based on a model that includes structural (space group, atoms in the asymmetric unit, heat factors, etc.), microstructural (concentration, crystal size, microstrain), and instrumental aspects (width at half height of diffraction peaks caused by the instrument).

\section{Experimental Methodology}

Unsupported catalysts were synthetized from oxides precursors $\mathrm{NiMoO}_{4}$ to $10,25,50$ and 75 wt\% of metal. The salts sources used were: nickel nitrate $\left(\mathrm{NiNO}_{3}\right)$, ammonium heptamolybdate $\left(\mathrm{NH}_{4}\right)_{6} \mathrm{MoO}_{24} \cdot 4 \mathrm{H}_{2} \mathrm{O}$ (Aldrich Chemical Co., 99.97\% purity) which is homogenized according to synthesis final oxide, once the corresponding homogenization is made, the mixture was dried at $120^{\circ} \mathrm{C}$ for $24 \mathrm{~h}$, and subsequently calcined at $500^{\circ} \mathrm{C}$ in order to obtain $\mathrm{NiMoO}_{4}$. The oxide precursors of transition metals were placed in a quartz reactor with a packed bed of 
0.5 inch of internal diameter and $3.28 \mathrm{ft}$ of length. Reactor with Teflon valves were used to isolate the sample at the end of reaction, avoiding its reduction by direct contact with air, since these materials are highly pyrophoric. The reactor was placed in a horizontal tubular furnace (Thermolyne, model 21100), with a chromelalumel thermocouple connected to a programmable temperature controller, which monitoring oven temperature. Heating ramps and were changed according to the final metal phase, reduced in an atmosphere of $\mathrm{NH}_{3}$ to form an oxynitride $\left(\approx 550^{\circ} \mathrm{C}\right)$. After this temperature, was passed to a mixture of different flows $\mathrm{CH}_{4} / \mathrm{H}_{2}$ to $700^{\circ} \mathrm{C}$ and final flow was maintained at the final temperature during $1 \mathrm{~h}$. The final carbide was cooled to room temperature. Finally the solid was passivated in $\mathrm{O}_{2} / \mathrm{Ar}$ mixture ( $1 \%$ of oxygen) to avoid the massive oxidation of catalyst.

The synthesized catalysts were characterized by X-ray diffraction (Bruker AXS, model D8-ADVANCE) with a scintillation counter and a monocromatizador incident beam. The samples were analyzed between 10 and 80 degrees at $2 \theta$ scale.

\section{Results}

Figure 1 exhibits the diffraction patterns of the carbide catalysts at different content (10, 25, 50, $75 \mathrm{wt} \% \mathrm{Mo})$. Segregated phases of $\mathrm{Ni}$ and Mo carbides and nickel carbide and molybdenum alone phases in the final sample were observed. The original oxide mixture was founded by the presence of $\mathrm{NiMoO}_{4}$ (200) plane, near to 27 grades, which was identified by the JCPDS card 18 0879 .

The presence of the oxide phases was attributable to the passivation process during the synthesis. The segrega tion and broken relation of $\mathrm{MoC}$ and $\mathrm{NiC}$ phases were expected to the different metal bonds with oxygen in the hexagonal lattice as demonstrated with mixtures of molybdenum and vanadium carbide, specifically for the heat formation of phases [4].

The nickel carbide phase presents a cubic structure according to the JCPDS card 14 - 0020 in the final sample. From a concentration of $10 \%$ by weight Mo, diffraction patterns exhibit a decrease of the characteristic peaks of the planes (111), (200) and (311) to $44.5^{\circ}, 51.9^{\circ}$ and $75.5^{\circ} 2 \theta$ respectively, it due to high content of crystalline nickel carbide phase.

On the other hand, it is noted that the materials are highly crystalline and are not affected when using constant flow of ammonia of $784 \mathrm{ml} / \mathrm{min}$. The materials that spotted higher intensities had larger crystal sizes were as shown in Table 1 for (111) and (200) planes specifically. However, the presence of Molybdenum carbide on the sample ((101) plane) showed a similar crystal size in all samples and oxides metal also. Those values obtained by calculation with the DRXwinsoftware.

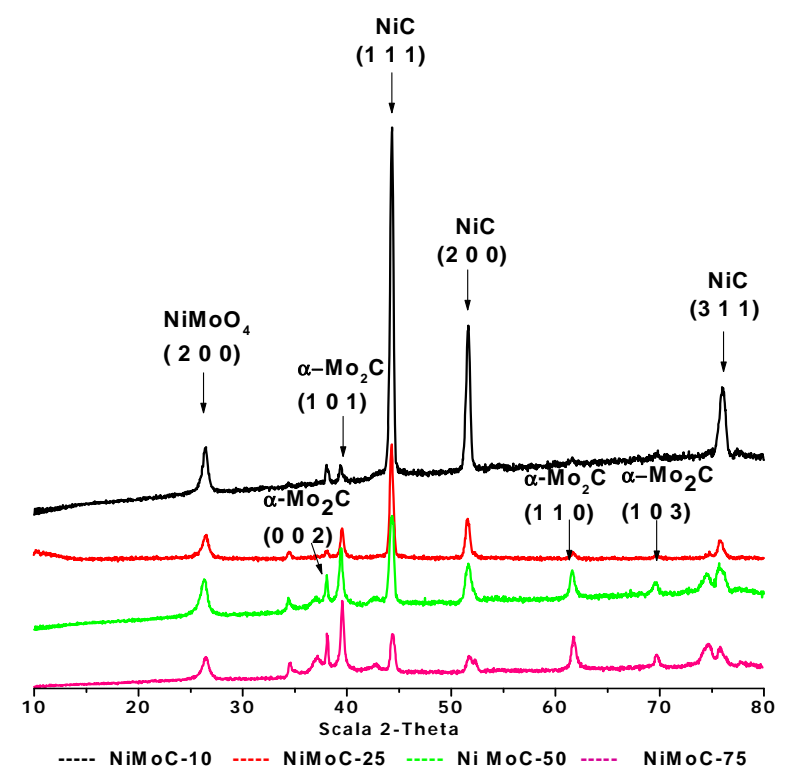

Figure 1. Diffraction patterns of the Ni-Mo carbides series synthesized at 10, 25, 50, 75 wt\% of Mo contents.

Table 1. Structural properties of the catalysts carbide of mass Ni-Mo, obtained by X-ray diffraction.

\begin{tabular}{cccccc}
\hline \multirow{2}{*}{ Catalysts } & \multicolumn{5}{c}{ Crystal Size $(\AA)$} \\
\cline { 2 - 6 } & $(111)$ & $(200)$ & $(311)$ & $(101)$ & $(200)$ \\
& $\mathrm{NiC}$ & $\mathrm{NiC}$ & $\mathrm{NiC}$ & $\alpha-\mathrm{Mo}_{2} \mathrm{C}$ & $\mathrm{NiMoO}_{4}$ \\
\hline NiMoC-10 & 330 & 254 & 173 & 426 & 163 \\
NiMoC-25 & 309 & 230 & 179 & 345 & 140 \\
NiMoC-50 & 232 & 146 & 61 & 300 & 123 \\
NiMoC-75 & 250 & 105 & 107 & 372 & 129 \\
\hline
\end{tabular}

The molybdenum carbide phase has two structures: hexagonal, which was identified in accordance with the card 01 - 1188, certain peaks being located in the range $39.89<2 \theta<75.3$ and the second structure showed an orthorhombic arrangement, it was identified with the JCPDS 72 - 1683 card. The principal peaks were located at 34.5, 38, 39.5 degrees at $2 \theta$ scale.

All samples showed a characteristic peak in the range of $2 \theta$ around $27^{\circ}$ in the plane (200) attributed to the presence of the mixture of bimetallic oxide, precursor used in the preparation phase, which decreases with the Mo loads in the samples.

In the series of bimetallic carbide catalysts was selected NiMoC-75 material for analyzed the phase segregated MoC, whose structure was modeled by Carine Crystallography Software 3.1 data are described in Figures 2 and $\mathbf{3}$, which was built on the basis of its space group and atomic positions.

The green spheres shown in Figures 2 and $\mathbf{3}$ represent the atoms of Mo and the black ones represent the $\mathrm{C}$ atoms. The Mo carbide has a hexagonal arrangement structure in the plane (101). This is consistent with the result 
obtained in the XRD analysis.

The method of synthesis used in the preparation of catalysts of transition metal carbides and conditions used in this study, it led to the formation of carbide phase-segregated Nickel and Molybdenum, due to the effect of temperature, atmosphere reduction and the heat differences of formation between them.

Figure 4 outlines the possible path of segregation of these materials in the case of Ni-Mo series.

\section{Conclusion}

The synthesis conditions used in the preparation of

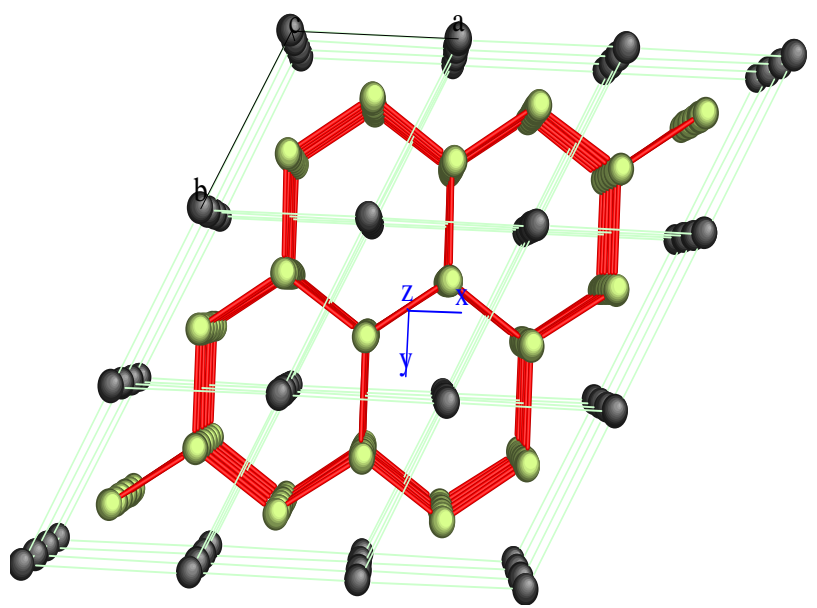

Figure 2. Crystallographic structure of Mo carbide obtained by Carine 3.1, (101) plane.

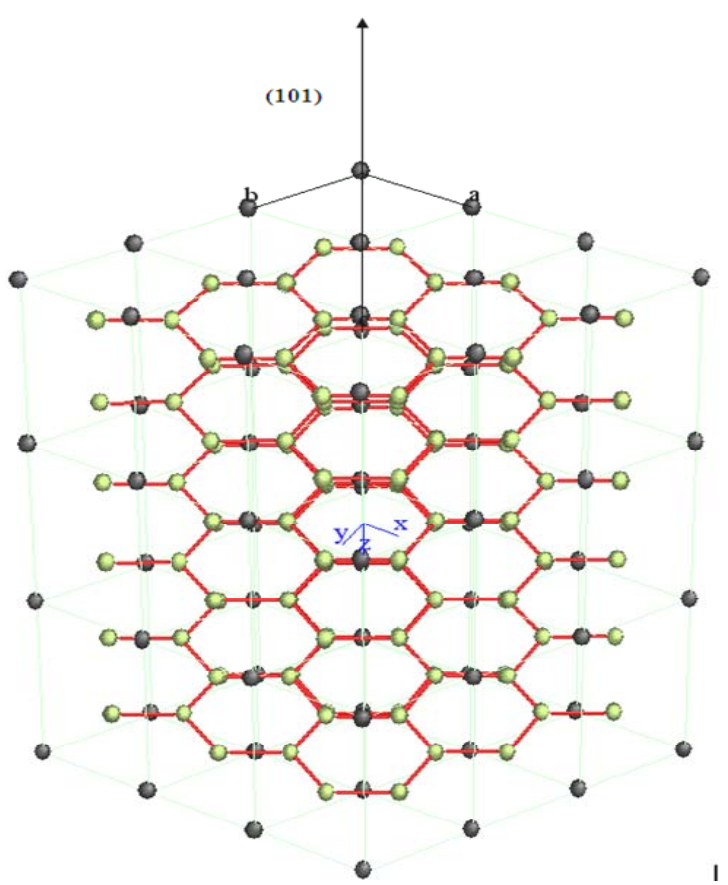

Figure 3. Crystallographic structure of molybdenum carbide with a hexagonal shape in the plane orientation (101).

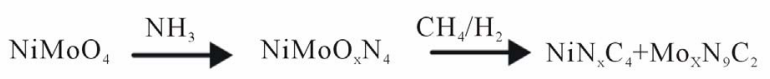

$\mathrm{NiC}+\mathrm{MoC}_{2}$

Figure 4. Possible segregation pathway of transition metals carbides.

catalysts of metal carbides of transition metals of Ni-Mo, using the Volpe and Boudart technique [5] yielded the Ni-Mo phase, secreted due to the effect of the synthesis temperature and the reducing atmosphere. The final phase obtained in the material mass of the Ni-Mo series was $\mathrm{NiC}$ at the planes (111), (200) and (311) for $\alpha \mathrm{MoC}$ in the plane (101). Those properties are similar to the application for example in hydrodesulphurization process where certain arrangements are required.

\section{Acknowledgements}

To Mexican Institute of Petroleum and specially Mr. Victor Manuel Menendez Ayala for the use of X-Ray Difractometer for the characterization of materials.

\section{REFERENCES}

[1] J. S. Lee, L. Volpe, F. H. Ribeiro and M. Boudart, "Molybdenum Carbide Catalysts. II. Topotactic Synthesis of Unsupported Powders,” Journal of Catalysis, Vol. 112, No. 1, 1988, pp. 44-53.

[2] S. Ramanathan and S. T. Oyama, "New Catalysts for Hydroprocessing: Transition Metal Carbides and Nitrides," The Journal of Physical Chemistry, Vol. 99, No. 44, 1995, pp. 16365-16372. doi:10.1021/j100044a025

[3] M. Vrinat, M. Breysse, C. Geantet, J. Ramirez and F. Massoth, "Effect of $\mathrm{MoS}_{2}$ Morphology on the HDS Activity of Hydrotreating Catalysts," Catalysis Letters, Vol. 26, No. 1-2, 1994, pp. 25-35.

[4] J. S. Lee, T. Oyama and M. Boudart, "Molybdenum Carbide Catalysts: I. Synthesis of Unsupported Powders," Journal of Catalysis, Vol. 106, No. 1, 1987, pp. 125-133. doi:10.1016/0021-9517(87)90218-1

[5] L. Volpe and M. Boudart, "Compounds of Molybdenum and Tungsten with High Specific Surface Area: I. Nitrides," Journal of Solid State Chemistry, Vol. 59, No. 3, 1985, pp. 332-347. doi:10.1016/0022-4596(85)90301-9 